\title{
The effects of addition of carbon dioxide and water vapor on the dynamic behavior of spherically expanding hydrogen/air premixed flames
}

\author{
Toshiyuki KATSUMI*, Yasuhito YOSHIDA*, Ryo NAKAGAWA*, Shinya YAZAWA*, \\ Masashi KUMADA*, Daisuke SATO**, Thwe Thwe Aung***, Nabiha CHAUMEIX**** \\ and Satoshi KADOWAKI** \\ *Department of Mechanical Engineering, Nagaoka University of Technology \\ 1603-1 Kamitomioka, Nagaoka 940-2188, Japan \\ E-mail: katsumi@mech.nagaokaut.ac.jp \\ **Department of System Safety, Nagaoka University of Technology \\ 1603-1 Kamitomioka, Nagaoka 940-2188, Japan \\ ${ }^{* * *}$ Collaborative Laboratories for Advanced Decommissioning Science, Japan Atomic Energy Agency \\ 4002 Oarai, Ibaraki 311-1393, Japan \\ ****Institut de Combustion, Aérothermique, Réactivité et Environnement, CNRS \\ 45071 Orléan Cedex 2, France
}

Received: 3 February 2021; Revised: 12 April 2021; Accepted: 22 April 2021

\begin{abstract}
Utilizing efficiently and securely hydrogen as clean energy source, it is required not only to analyze the experimental data under a certain condition but also to create the mathematical model for the prediction of flame propagation velocity under various conditions. Thus, it is significant to understand the characteristics of dynamic behavior of hydrogen/air premixed flames and to elucidate the effects of addition of inert gas, i.e. carbon dioxide $\mathrm{CO}_{2}$ and water vapor $\mathrm{H}_{2} \mathrm{O}$. We performed the experiments of hydrogen explosion in two types of closed chambers to observe spherically expanding flames using Schlieren photography. Wrinkles on the flame surface were clearly observed in low equivalence ratios. Analyzing the Schlieren images, the flame propagation velocity depending on the flame radius was obtained. Increasing the addition of inert gas, the propagation velocity decreased, especially in the case of $\mathrm{CO}_{2}$ addition. The propagation velocity increased monotonically as the flame radius became larger. The appearance of flame acceleration was found, which was caused by the evolution of wrinkles on the flame surface. Moreover, the Markstein length decreased as the concentration of inert gas became higher, indicating that the addition of inert gas promoted the instability of hydrogen flames. Furthermore, the wrinkling factor, closely related with the increment in propagation velocity, decreased as the inert-gas concentration became higher. The wrinkling factor normalized by the propagation velocity of flat flame increased, on the other hand, under the conditions of high inert-gas concentration, except for near the quenching conditions. This indicated that the addition of $\mathrm{CO}_{2}$ or $\mathrm{H}_{2} \mathrm{O}$ promoted the unstable motion of hydrogen flames, which could be due to the enhancement of the diffusive-thermal effect. Based on the characteristics of dynamic behavior of hydrogen flames, the parameters used in the mathematical model on propagation velocity including flame acceleration was obtained, and then the flame propagation velocity under various conditions was predicted.
\end{abstract}

Keywords : Hydrogen-air premixed combustion, Spherically expanding flame, Carbon dioxide, Water vapor, Dynamic behavior, Flame acceleration, Intrinsic instability

\section{Introduction}

Currently, approximately $80 \%$ of world's energy demand is met by fossil fuels including coal, petroleum, and natural gases (Newell et al., 2020), and the energy consumption is expected to further increase in the future. However, the fossil 
fuels produce the carbon dioxide $\mathrm{CO}_{2}$ in combustion, accelerating the global warming. Since the reserve of fossil fuels is limited, moreover, there is a concern of the depletion and energy crisis in the end. In order to deal with such increasingly severe environmental/energy situation, the reduction of $\mathrm{CO}_{2}$ emission followed by transition to the energy society that does not excessively depend on the fossil fuels is a worldwide important issue.

Hydrogen is one of the potential candidates to be substituted for the fossil fuels. Since hydrogen $\mathrm{H}_{2}$ does not contain carbon in the molecular structure, almost only water vapor $\mathrm{H}_{2} \mathrm{O}$ is released into the environment as end-product of its combustion without emitting $\mathrm{CO}_{2}$. Some hydrogen-based energy systems, e.g. internal combustion engines, have been studied (Acar and Dincer, 2020). Additionally, hydrogen has advantages of high fuel-to-power conversion efficiency of fuel cells (Haseli, 2018) and many choices of storage configuration, i.e. compressed hydrogen, liquid hydrogen and storage materials (Niaz et al., 2015). However, hydrogen is well-known to be excellent combustible due to wide flammable range (i.e. hydrogen concentration to enable burning in air is 4-75 vol\%) and to low minimum ignition energy $(0.017 \mathrm{~mJ})$, and its burning and propagation velocities are significantly higher than those of other fuels, which carries high risk of serious accidents (Mazloomi and Gomes, 2012; Dutta, 2014).

During the severe accident in nuclear power plants, the reaction of heated zirconium metal, primary material for fuel cladding, with steam and water radiolysis generates hydrogen, which can result in short term overpressure or detonation forces that may exceed the strength of the containment structure (International Atomic Energy Agency (IAEA), 2011). Given the hazardous characteristics, efficient combustion management must be developed for the safety operation and hazard mitigation of hydrogen-related technologies. The combustion characteristics, especially flame propagation velocity that affects the extent of damage at explosion, need to be correctly estimated and then be properly controlled. As a possible approach, the addition of inert gas is known to have predominant effects on the hydrogen explosion/combustion characteristics.

There have been various reports that experimentally clarified the effects of inert-gas addition, i.e. helium He, argon Ar, nitrogen $\mathrm{N}_{2}, \mathrm{CO}_{2}$ and $\mathrm{H}_{2} \mathrm{O}$, on the explosion/combustion characteristics of hydrogen premixtures (Qiao et al., 2007; Bane et al., 2011; Zhang et al., 2012; Cheikhravat et al., 2015; Li et al., 2019; Yan et al., 2020; Gong et al., 2020); the primary effects are decreasing burning/propagation velocities and mitigation of explosion pressure.

For example, Li et al. (2018) studied the hydrogen-cloud explosion under inert-gas atmosphere; the average flame propagation velocity decreased monotonically in the order of $\mathrm{He}, \mathrm{Ar}$ and $\mathrm{N}_{2}$ regardless of equivalence ratio. Moreover, Li et al. (2016) investigated the combustion characteristics of hydrogen/air/inert gas $\left(\mathrm{N}_{2}\right.$ or $\left.\mathrm{CO}_{2}\right)$ premixtures under fuel lean conditions; for $\mathrm{H}_{2} / \mathrm{N}_{2}$ mixture, the suppression effect on burning velocity was resulted from the modified specific heat of mixtures and the decreased heat release; for $\mathrm{H}_{2} / \mathrm{CO}_{2}$ mixture, further suppression effect was observed owing to both thermal and chemical effects.

Duan and Liu (2017) examined the combustion characteristics of hydrogen/air premixtures diluted with $\mathrm{N}_{2}$ and/or $\mathrm{H}_{2} \mathrm{O}$; the flame propagation velocity decreased by $64.3 \%$ with increasing the dilution ratio from 10 to $40 \%$ at the initial temperature of $393 \mathrm{~K}$, initial pressure of $0.1 \mathrm{MPa}$ and equivalence ratio of 1.0. Wang et al. (2019) experimentally analyzed the explosion characteristics of hydrogen/air premixtures diluted with inert gases $\left(\mathrm{Ar}, \mathrm{N}_{2}\right.$ and $\left.\mathrm{CO}_{2}\right)$ over a wide range of equivalence ratios under the conditions of room temperature $(298 \mathrm{~K})$ and sub-atmospheric pressures $(40,60,80$, and 100 $\mathrm{kPa}$ ); the maximum explosion pressure, maximum pressure rise rate and deflagration index depended largely on the initial pressure, diluent type and fraction, i.e. these parameters were mitigated with the decrease of initial pressure and the increase of diluent fraction while showing that among these inert gases, $\mathrm{CO}_{2}$ was the most effective, followed by $\mathrm{N}_{2}$ and Ar. Moreover, to develop efficient internal combustion engines based on hydrogen combustion, Morovatiyan et al. (2020) studied the effects of $\mathrm{Ar}$ as a working fluid on the characteristics of $\mathrm{H}_{2} / \mathrm{O}_{2} / \mathrm{N}_{2} / \mathrm{Ar}$ premixed flames at a wide range of equivalence ratios (0.2-3.0), initial pressures of 0.2-0.6 bar and initial temperature of $298 \mathrm{~K}$; increasing the concentration of $\mathrm{Ar}$ in the mixture increased the burning velocity and flame speed while extending the lean flammability limit.

During the propagation of hydrogen/air premixed flames, wrinkles on the flame surface appears, which is attributed to hydrodynamic and diffusive-thermal instabilities (Williams, 1985). The presence of cellular structure increases the flame-surface area, which can significantly augment the flame propagation velocity compared with smooth flames (Kitagawa, 2014; Kim et al., 2014). Thus, correctly understanding the accelerating effects in flame propagation is crucial. The effects of equivalence ratio, initial temperature and initial pressure on the morphology of cellular flames and propagation property have been explored using the closed combustion chambers by many researchers (Liu et al., 2012; Sun et al., 2012; Yang et al., 2016); the results have provided some primary knowledges as follows: (1) Increase in equivalence ratio mainly declines the diffusive-thermal instability. (2) Rise in initial temperature mainly suppresses the 
hydrodynamic instability. (3) Rise in initial pressure mainly causes the significant acceleration of the hydrodynamic instability. (4) Critical flame radius represents the timing of onset of cellular instability.

To utilize efficiently and securely hydrogen, it is required not only to analyze the experimental data under a certain condition but also to create the mathematical model for the prediction of flame propagation velocity under various conditions. Some of the authors have investigated the dynamic behavior of spherically expanding hydrogen flames in a closed chamber using a high speed Schlieren photography and image processing (Katsumi et al., 2017a; Katsumi et al., 2017b); the flame propagation velocity depending on the equivalence ratio and initial temperature has been characterized, resulting that the flame propagation model taken account of the flame acceleration caused by cellular instability has been obtained.

In the present study, to provide further knowledges on control of hydrogen combustion by inert-gas addition, we elucidate the effects of inert gases, $\mathrm{CO}_{2}$ or $\mathrm{H}_{2} \mathrm{O}$, on the dynamic behavior of hydrogen/air premixed flames, employing the optical visualization system. Moreover, we obtain the parameters used in the mathematical model including flame acceleration, based on the flame-propagation modeling method created in our previous work, to predict the flame propagation velocity under various conditions.

\section{Experimental procedures}

\subsection{Experiments at NUT}

The closed chamber was used for explosion experiments at NUT (Nagaoka University of Technology). As shown in Fig. 1, the closed chamber had four quartz windows, whose diameters were $300 \mathrm{~mm}$, on the side walls (Katsumi et al., 2017a; Katsumi et al., 2017b). The internal shape was an intersection of three cylinders and inner volume was 73 L. For the ignition of mixture, the closed chamber had two electrodes which were inserted vertically and oppositely. The overall schematic view of the experimental apparatus was shown in Fig.2. The flame propagation phenomena were observed by Schlieren photography (Mizojiri SL-350) through the quartz windows and recorded by using a high speed video camera (Photoron SA-X) which was operated at $10,000 \mathrm{fps}$ with $1024 \times 1024$ pixels image resolution. The initial pressure in the closed chamber was measured by a capacitive pressure sensor (Kistler 6045A31), and also the initial temperature was measured by a thermocouple (T-type).

In the experiments, the closed chamber was vacuumed and filled with air, carbon dioxide and hydrogen, considering each partial pressure. After that, the mixture was ignited at the center of the closed chamber. By a trigger from the ignition controller, the high speed video camera and the data logger for pressure were synchronized. The mixture ratio of hydrogen and air in the range of equivalence ratio was 0.5 and 1.0. To evaluate the addition of $\mathrm{CO}_{2}$ on the characteristics of dynamic behavior, the concentration of $\mathrm{CO}_{2}$ in the mixture was $0-40 \%$. The initial pressure and temperature of mixture were kept at constant, $348 \mathrm{~K}$ and $101 \mathrm{kPa}$, respectively.

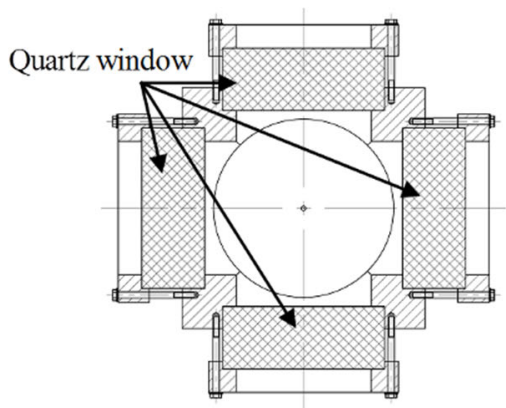

Horizontal cross-sectional view (Left)

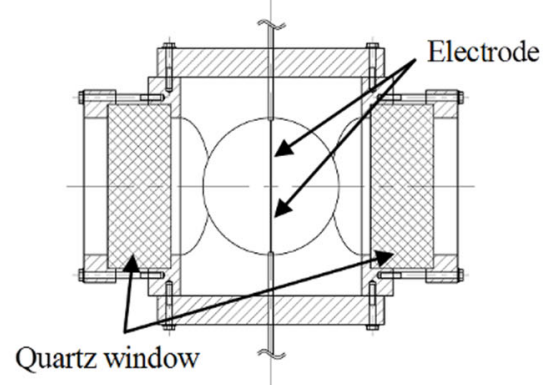

Vertical cross-sectional view (Right)

Fig. 1. Schematic view of the closed chamber at NUT 


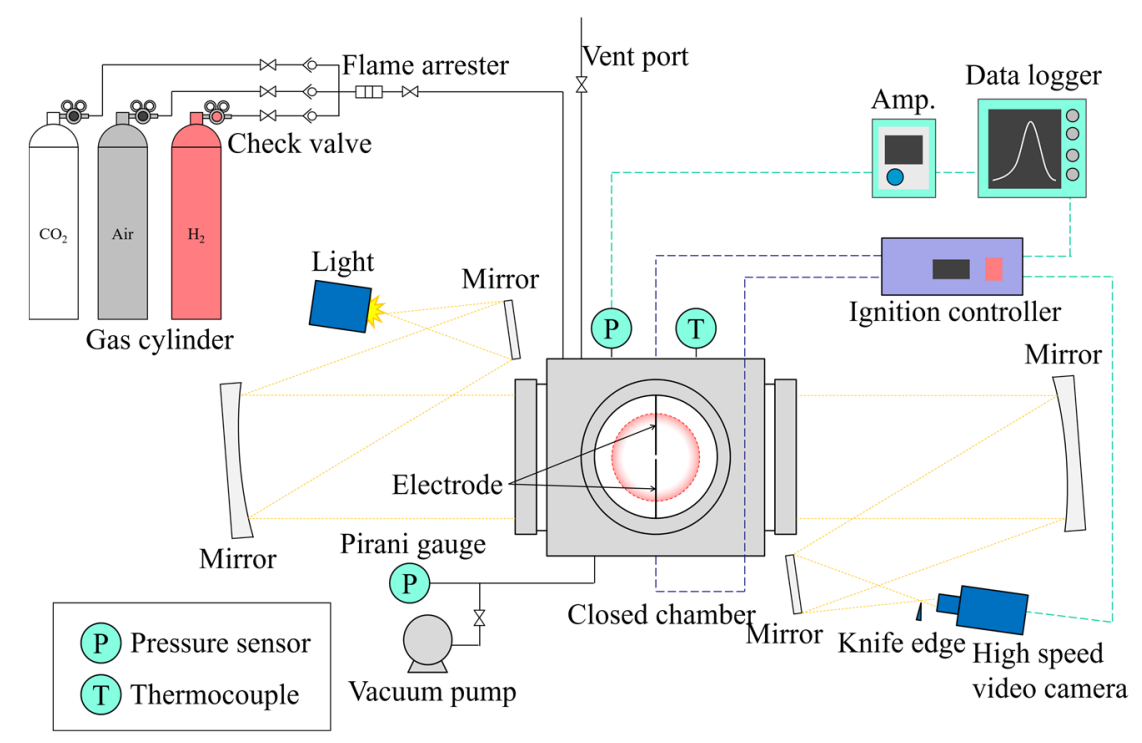

Fig. 2 Overall schematic view of the experimental apparatus at NUT

\subsection{Experiments at ICARE}

The spherical chamber shown in Fig. 3 was used for explosion experiments at ICARE (Institut de Combustion, Aérothermique, Réactivité et Environnement). This chamber had four windows in horizontal with diameter of $97 \mathrm{~mm}$ and spherical space with internal volume of $56 \mathrm{~L}$. Moreover, the spherical chamber had a hot oil jacket and was covered with glass wool to heat the mixture. Figure 3 shows the overview of the closed chamber at ICARE. The propagation of hydrogen flames was observed using the Schlieren photography. Figure 4 shows the schematic diagram of Schlieren apparatus. The Schlieren image was taken with a high speed video camera (Phantom V1611 and V1210) under the frame rate of $7500,10000,15000,25000,25392 \mathrm{fps}$, and the resolution of $768 \times 768$ pixels.

In the experiments, the spherical chamber was vacuumed, and then water, hydrogen and air were injected sequentially. Water was completely evaporated during the injection procedure. After the mixture became steady state, it was ignited at the center of the spherical chamber. The equivalence ratio was set to 0.5 and 1.0 , and the concentration of $\mathrm{H}_{2} \mathrm{O}$ was changed to $0-30 \%$. The initial temperature and pressure were $348 \mathrm{~K}$ and $101 \mathrm{kPa}$, respectively, similar to the experimental conditions at NUT.
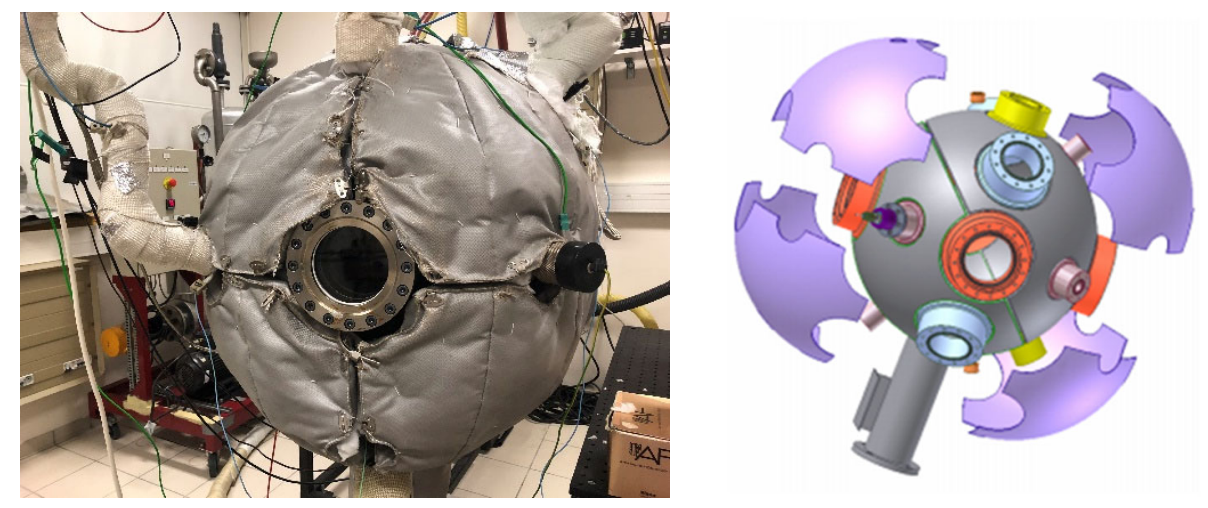

Fig. 3 Overview of the spherical chamber at ICARE 


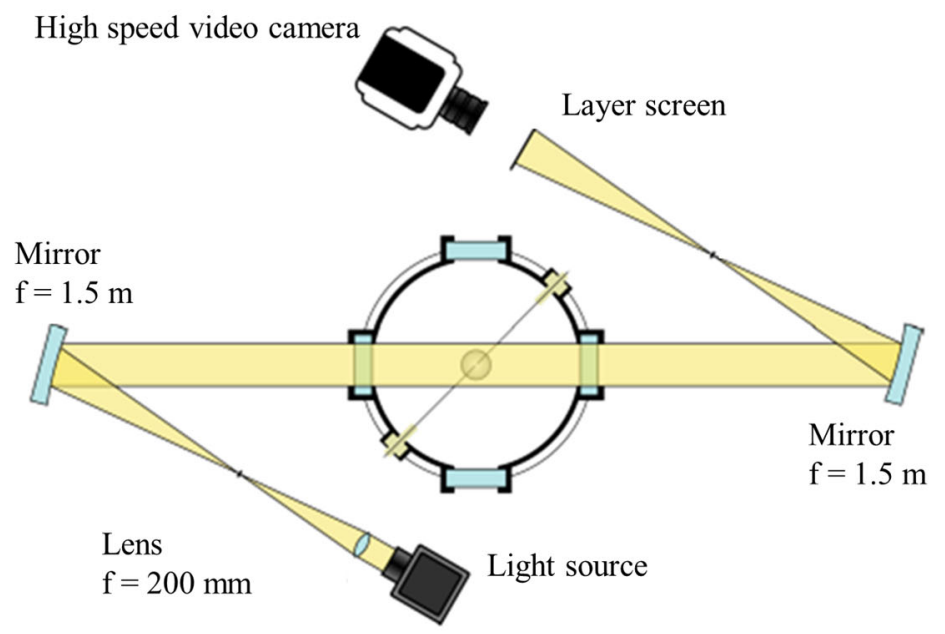

Fig. 4 Schematic diagram of Schlieren apparatus at ICARE

\section{Results and discussion}

\subsection{Schlieren images}

Figure $5(\phi=1.0)$ and Fig. $6(\phi=0.5)$ show the Schlieren images of spherically expanding $\mathrm{H}_{2} /$ air flames at NUT. In each equivalence ratio, the flame shapes observed at approximately $2.0,4.0,6.0$ and $8.0 \mathrm{~cm}$ in radius are presented. The propagation velocity of the $\phi=1.0$ flame is larger than that of the $\phi=0.5$ flame, because of larger burning velocity. Wrinkled flames (Cellular flames) form in both conditions, and wrinkles on the flame surface become clear with increasing the flame radius. Compared with the $\phi=1.0$ case, prominent wrinkled surface is observed at $\phi=0.5$. This is because that the diffusive-thermal instability becomes stronger. The obtained results clarify that the wrinkled-flame surface develops further at low equivalence ratios.

The Schlieren images of $\mathrm{H}_{2}$ /air flames at ICARE are shown in Fig. $7(\phi=1.0)$ and Fig. $8(\phi=0.5)$. We find that the flame shapes at approximately 1.0, 2.0, 3.0 and $4.0 \mathrm{~cm}$ in radius are almost consistent with the results obtained at NUT. Wrinkles grow along with the development of flame radius and become prominent at $\phi=0.5$. On the other hand, wrinkles on the flame surface are not so clear at $\phi=1.0$. This is because that the flame shape is observed in the range of flame radius less than $4 \mathrm{~cm}$. When the flame radius is approximately $8.0 \mathrm{~cm}$, we can find clear wrinkles at $\phi=1.0$, similar to the results obtained at NUT (see Fig. 5).

We add carbon dioxide and water vaper as inert gas to the hydrogen/air mixture. The Schlieren images of $\mathrm{H}_{2} /$ air/ $\mathrm{CO}_{2}$ and $\mathrm{H}_{2} /$ air/ $\mathrm{H}_{2} \mathrm{O}$ flames at NUT and ICARE, respectively, are shown in Fig. $9(\phi=1.0)$. The flame propagation in $\mathrm{H}_{2} /$ air mixture with $\mathrm{H}_{2} \mathrm{O}$ of $40 \%$ is not observed. As the addition of $\mathrm{CO}_{2}$ or $\mathrm{H}_{2} \mathrm{O}$ increases, the flame surface becomes more wrinkle. The present results denote that the addition of inert gas promotes the instability of flame surface. Moreover, the expanding velocity decreases as the concentration of inert gas becomes higher, especially in the $\mathrm{CO}_{2}$ case. Figure 10 shows the Schlieren images of the $\phi=0.5$ flame. We do not catch the flame propagation in $\mathrm{H}_{2} /$ air mixture with $\mathrm{H}_{2} \mathrm{O}$ of $30 \%$ at $\phi=0.5$. The unstable behavior of flame surface at high concentration of inert gas is found.

The addition of $\mathrm{CO}_{2}$ or $\mathrm{H}_{2} \mathrm{O}$ has a great influence on the dynamic behavior of spherically expanding hydrogen/air premixed flames. Thus, we need to elucidate the effects of inert gas on the flame propagation velocity to obtain the parameters used in the mathematical model including flame acceleration. 


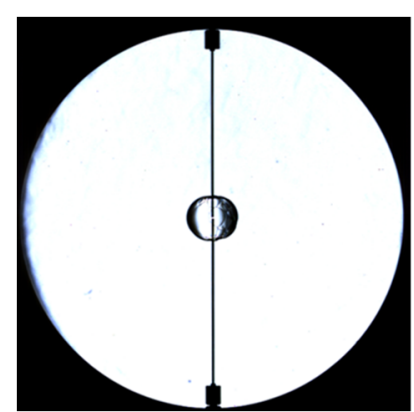

$r_{\mathrm{b}}=2.0 \mathrm{~cm}, t=1.2 \mathrm{~ms}$

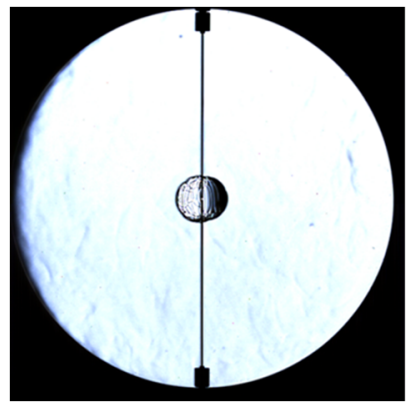

$r_{\mathrm{b}}=2.0 \mathrm{~cm}, t=4.0 \mathrm{~ms}$

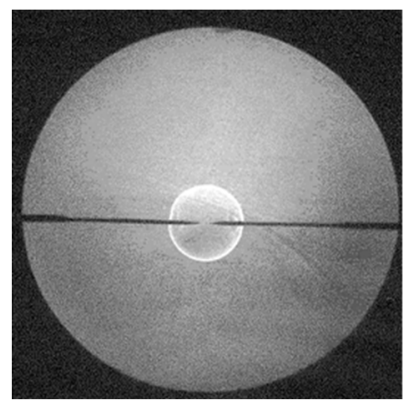

$r_{\mathrm{b}}=1.0 \mathrm{~cm}, t=0.7 \mathrm{~ms}$

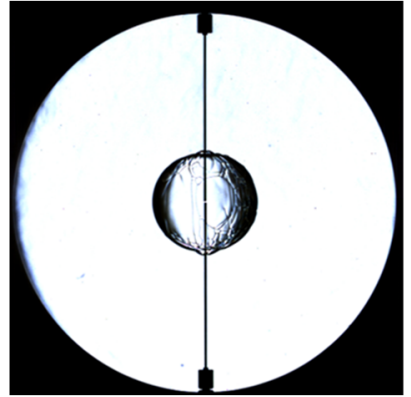

$r_{\mathrm{b}}=4.0 \mathrm{~cm}, t=2.5 \mathrm{~ms}$

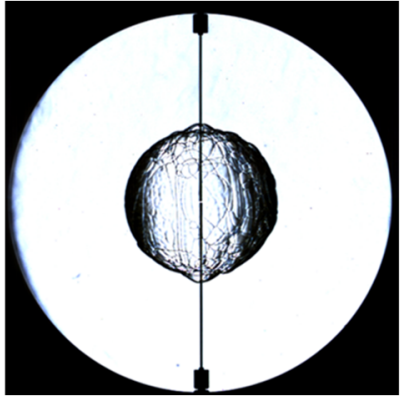

$r_{\mathrm{b}}=6.0 \mathrm{~cm}, t=3.6 \mathrm{~ms}$

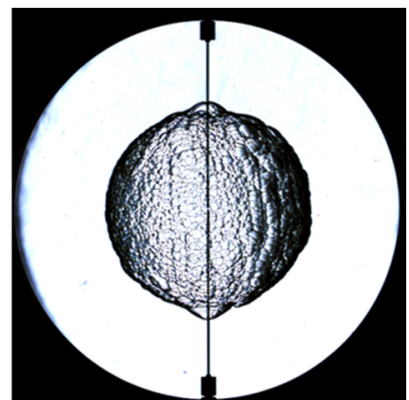

$r_{\mathrm{b}}=8.0 \mathrm{~cm}, t=4.7 \mathrm{~ms}$

Fig. 5 Schlieren images of $\mathrm{H}_{2}$ /air flame $(\phi=1.0)$ at NUT

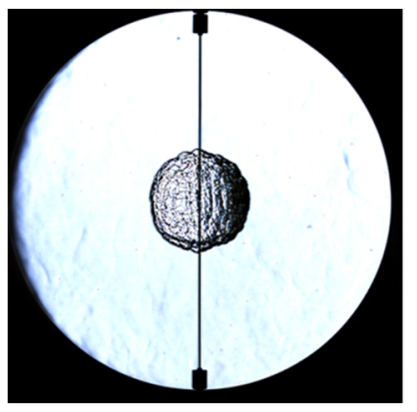

$r_{\mathrm{b}}=4.0 \mathrm{~cm}, t=8.3 \mathrm{~ms}$

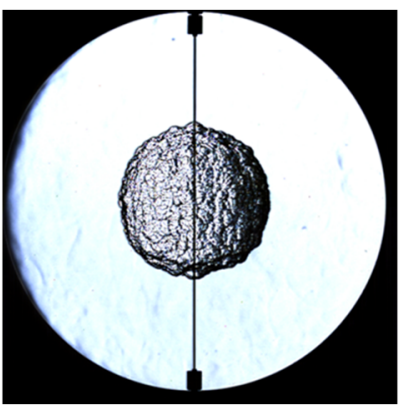

$r_{\mathrm{b}}=6.0 \mathrm{~cm}, t=11.9 \mathrm{~ms}$

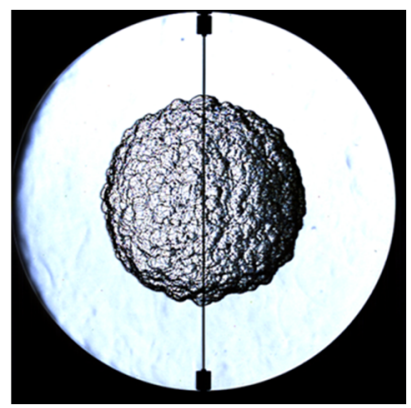

$r_{\mathrm{b}}=8.0 \mathrm{~cm}, t=15.3 \mathrm{~ms}$

Fig. 6 Schlieren images of $\mathrm{H}_{2}$ /air flame $(\phi=0.5)$ at NUT

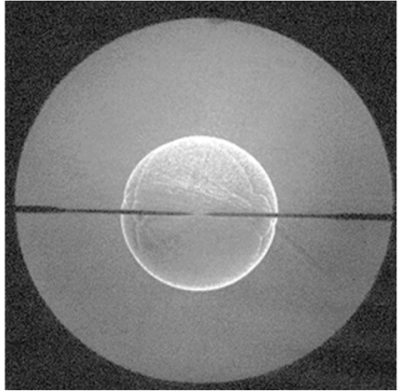

$r_{\mathrm{b}}=2.0 \mathrm{~cm}, t=1.4 \mathrm{~ms}$

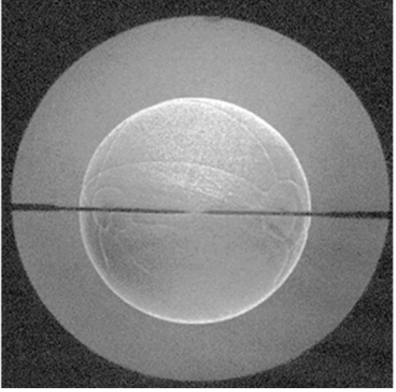

$r_{\mathrm{b}}=3.0 \mathrm{~cm}, t=2.0 \mathrm{~ms}$

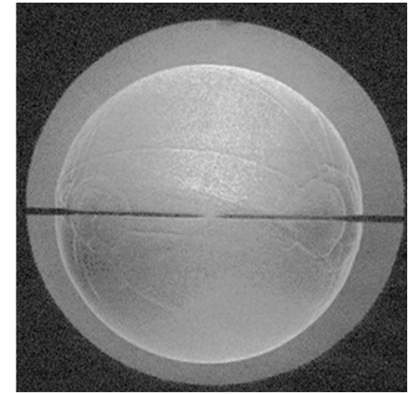

$r_{\mathrm{b}}=4.0 \mathrm{~cm}, t=2.6 \mathrm{~ms}$

Fig. 7 Schlieren images of $\mathrm{H}_{2} /$ air flame $(\phi=1.0)$ at ICARE

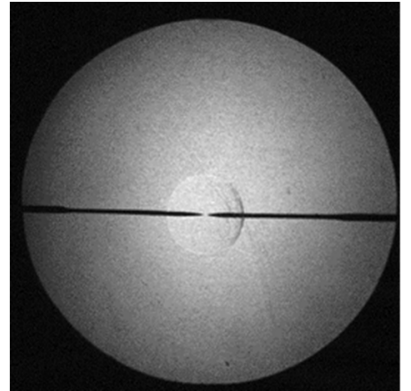

$r_{\mathrm{b}}=1.0 \mathrm{~cm}, t=2.0 \mathrm{~ms}$

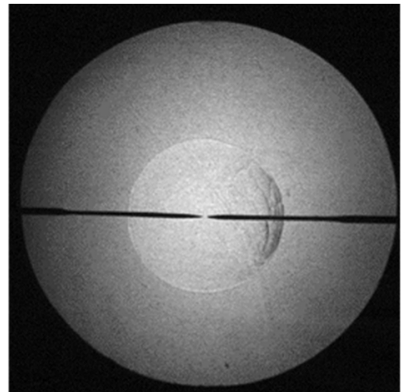

$r_{\mathrm{b}}=2.0 \mathrm{~cm}, t=4.7 \mathrm{~ms}$

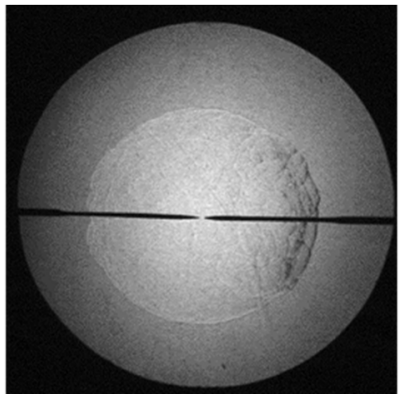

$r_{\mathrm{b}}=3.0 \mathrm{~cm}, t=7.0 \mathrm{~ms}$

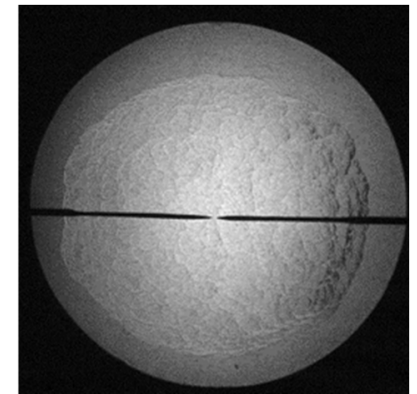

$r_{\mathrm{b}}=4.0 \mathrm{~cm}, t=9.1 \mathrm{~ms}$

Fig. 8 Schlieren images of $\mathrm{H}_{2} /$ air flame $(\phi=0.5)$ at ICARE 


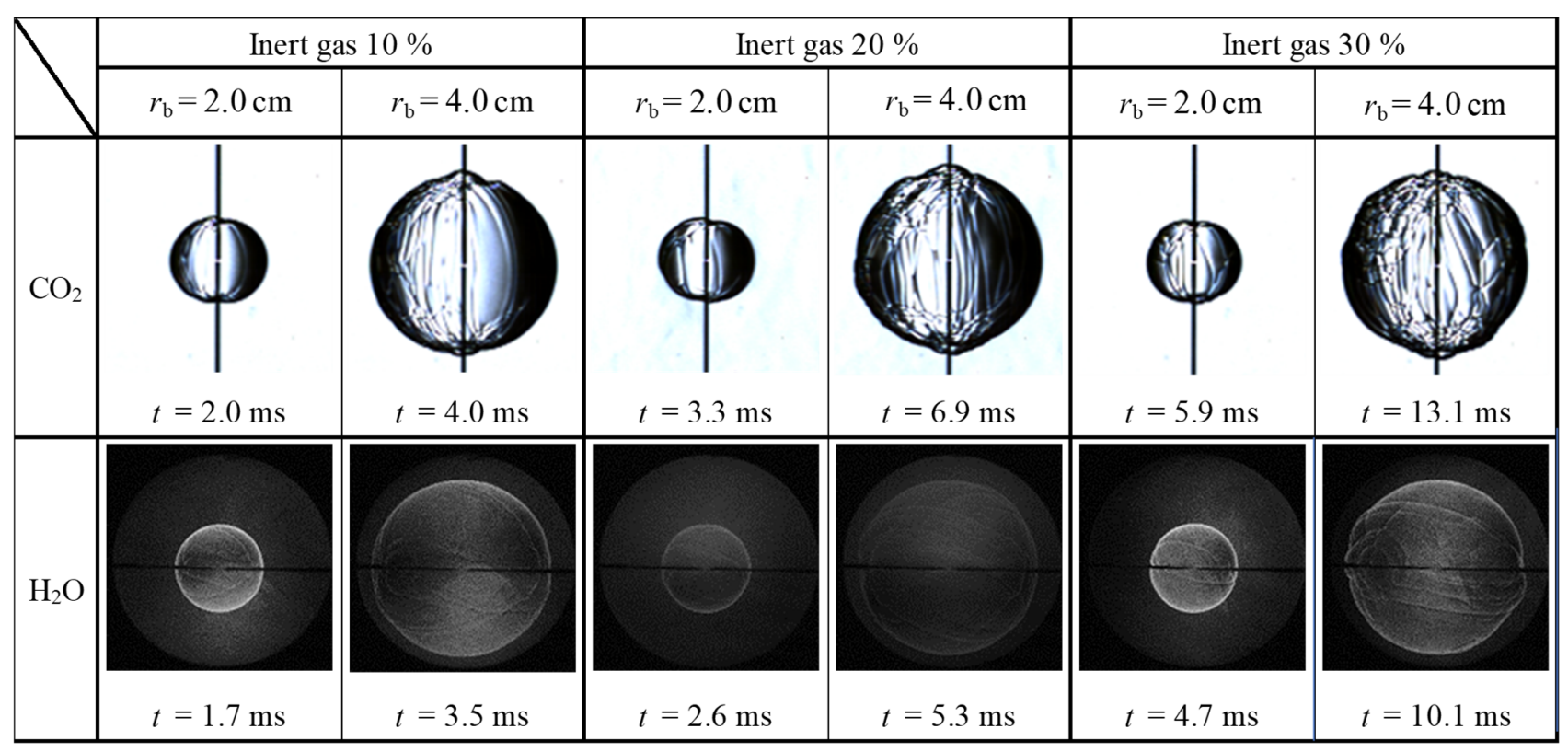

Fig. 9 Schlieren images of $\mathrm{H}_{2} /$ air/ $/ \mathrm{CO}_{2}$ and $\mathrm{H}_{2} /$ air/ $\mathrm{H}_{2} \mathrm{O}$ flames $(\phi=1.0)$ at NUT and ICARE

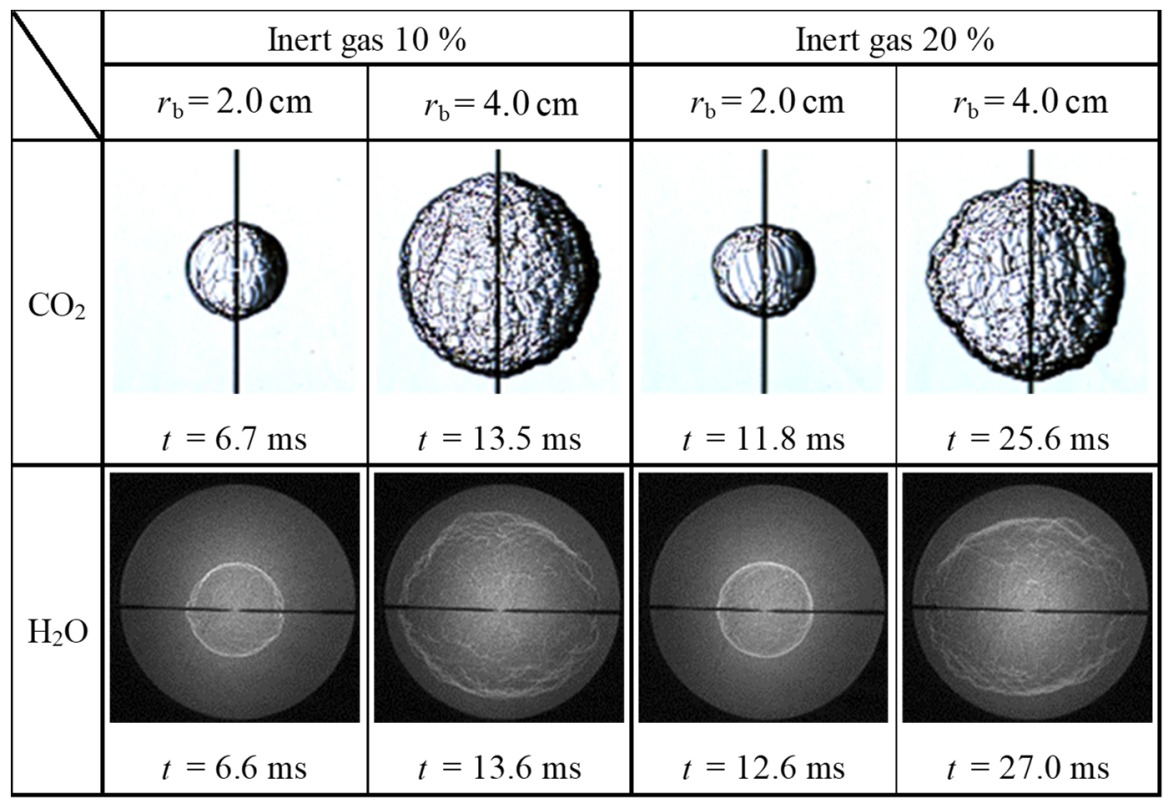

Fig. 10 Schlieren images of $\mathrm{H}_{2} /$ air/ $\mathrm{CO}_{2}$ and $\mathrm{H}_{2} /$ air/ $/ \mathrm{H}_{2} \mathrm{O}$ flames $(\phi=0.5)$ at NUT and ICARE 


\subsection{Propagation phenomena}

We analyzed the obtained Schlieren video frame-by-frame to investigate propagation phenomena. The flame radius $r_{\mathrm{b}}$ was estimated from the area occupied by flame shape which obtained by binarizing the Schlieren images using a constant grey value, and then the flame propagation velocity $S_{\mathrm{b}}$ was derived by differentiating the flame radius with respect to the time.

Figure 11 shows the flame propagation velocity depending on the flame radius at $\phi=1.0$, considering the addition of inert gas. When the mixture consists only of hydrogen and air, the flame propagation velocity obtained at $\mathrm{NUT}\left(\mathrm{CO}_{2}\right.$ $=0 \%)$ is almost consistent with that obtained at ICARE $\left(\mathrm{H}_{2} \mathrm{O}=0 \%\right)$ in the range of $r_{\mathrm{b}}<4 \mathrm{~cm}$. As the addition of $\mathrm{CO}_{2}$ or $\mathrm{H}_{2} \mathrm{O}$ increases, the flame propagation velocity decreases, especially in the $\mathrm{CO}_{2}$ addition case. Next, we show the flame propagation velocity at $\phi=0.5$ in Fig. 12. The flame propagation velocity decreases as the addition of inert gas increases. In all cases, the propagation velocity increases monotonically as the flame radius becomes larger. We find here the appearance of flame acceleration, which is caused by the evolution of wrinkles on the flame surface.

The propagation velocity of flat flame $\beta$ and the Markstein length including the thermal-expansion effect $L$ ' were estimated from the data of experiments repeated three times. In the range of small radius, the flame propagation velocity is not affected by wrinkles because of smooth flame surface, but affected strongly by the flame stretch. We estimate $\beta$ and $L$ ' through the experimental data, based on the relation between the flame propagation velocity and the flame stretch rate (Lamoureux et al., 2003; Katsumi et al., 2017a):

$$
S_{b}=-L^{\prime} \kappa+\beta
$$

where $\kappa$ is the flame stretch rate, and it is evaluated by

$$
\kappa=2 S_{b} / r_{b}
$$

Figure 13 shows the propagation velocity of flat flame depending on the concentration of inert gas. In Comparison with the data obtained from the literature (Iijima et al., ) considering the thermal-expansion effect, it is indicated that our results are plausible. As the inert-gas concentration becomes higher, the propagation velocities of flat flames decrease in the both equivalence ratios. When $\phi=1.0$, the decrement of propagation velocity in the case of $\mathrm{CO}_{2}$ addition is large compared with the $\mathrm{H}_{2} \mathrm{O}$ addition case. When $\phi=0.5$, on the other hand, both the decrements of propagation velocities are almost the same. The Markstein length including the thermal-expansion effect is shown in Fig. 14. The Markstein length at $\phi=0.5$ is lower than that at $\phi=1.0$, which is due to higher level of diffusive-thermal instability. As the concentration of inert gas becomes higher, the Markstein length decreases. This indicates that the addition of inert gas promotes the instability of hydrogen flames at $\phi=1.0$ and 0.5 .

To express the flame acceleration caused by the evolution of wrinkles when the flame radius is larger than the critical flame radius which means the onset radius of flame acceleration, we employed the increment of propagation velocity $\Delta S_{b}$ as shown in the following relation (Katsumi et al., 2017a):

$$
\Delta S_{b}=\alpha \ln \left(\frac{r_{b}}{r_{0}}\right)
$$

where $\alpha$ is the wrinkling factor and $r_{0}$ is the critical flame radius. The mathematical model on propagation velocity including flame acceleration (Katsumi et al., 2017b) is written as follows:

$$
S_{b}=\alpha \ln \left(\frac{r_{b}}{r_{0}}\right)-L^{\prime} \kappa+\beta
$$

Analyzing the experimental data, we obtain the parameters as follows used in the mathematical model, so that the flame propagation velocity under various conditions is predicted by means of the above relation.

Figure 15 and 16 show the wrinkling factor and critical flame radius depending on the concentration of inert gas. We omit the results of $\mathrm{H}_{2} \mathrm{O}$ addition case at $\phi=1.0$ because sufficient acceleration is not confirmed. As the inert-gas concentration becomes larger, the wrinkling factor decreases, which is due mainly to the decrease of burning velocity. 
We normalize the wrinkling factor by the propagation velocity of flat flame to elucidate the instability characteristics. The normalized wrinkling factor is shown in Fig. 17. As the concentration of inert gas becomes higher, the normalized wrinkling factor increases, except for two cases at $\phi=0.5\left(\mathrm{CO}_{2}\right.$ of $30 \%$ and $\mathrm{H}_{2} \mathrm{O}$ of $\left.20 \%\right)$, where two cases are near the quenching conditions. Moreover, the normalized wrinkling factor of the $\phi=0.5$ flame is larger than that of the $\phi=1.0$ flame. The obtained results indicate that the addition of $\mathrm{CO}_{2}$ or $\mathrm{H}_{2} \mathrm{O}$ and reduction of equivalence ratio promote the instability of hydrogen flames, which could be due to the enhancement of the diffusive-thermal effect. It is found that the critical flame radius become small as the instability promotes.

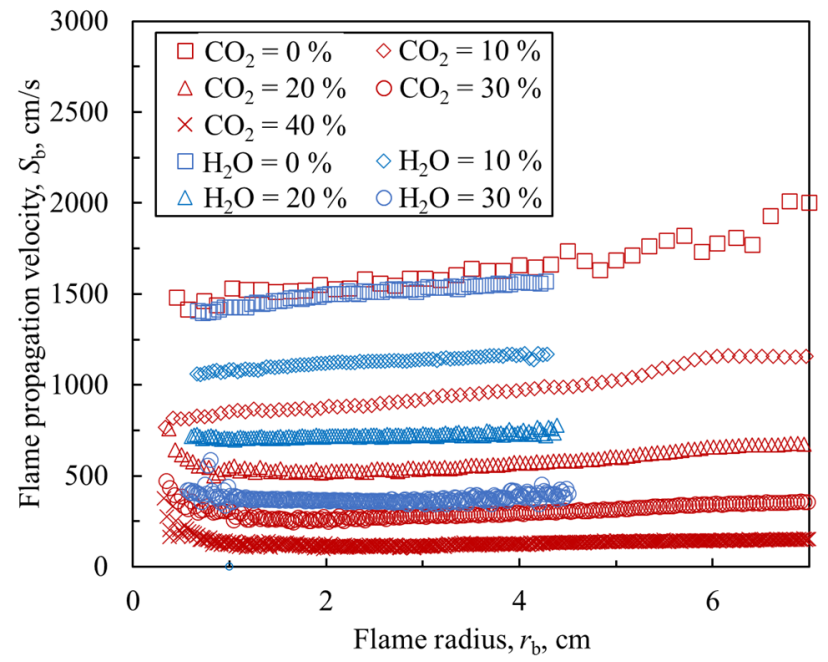

Fig. 11 Flame propagation velocity depending on the flame radius at $\phi=1.0$

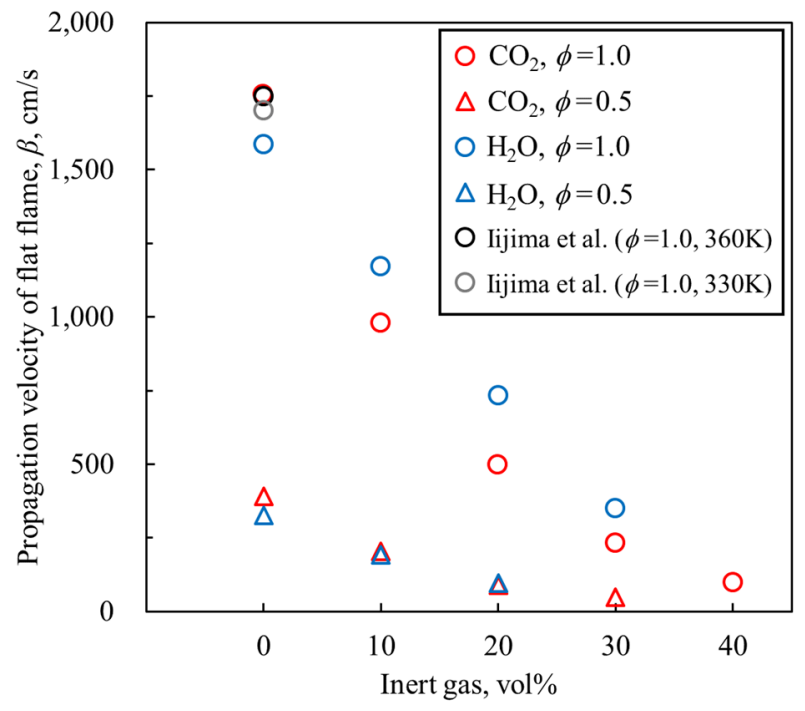

Fig. 13 Propagation velocity of flat flame depending on the concentration of inert gas at $\phi=1.0$ and 0.5

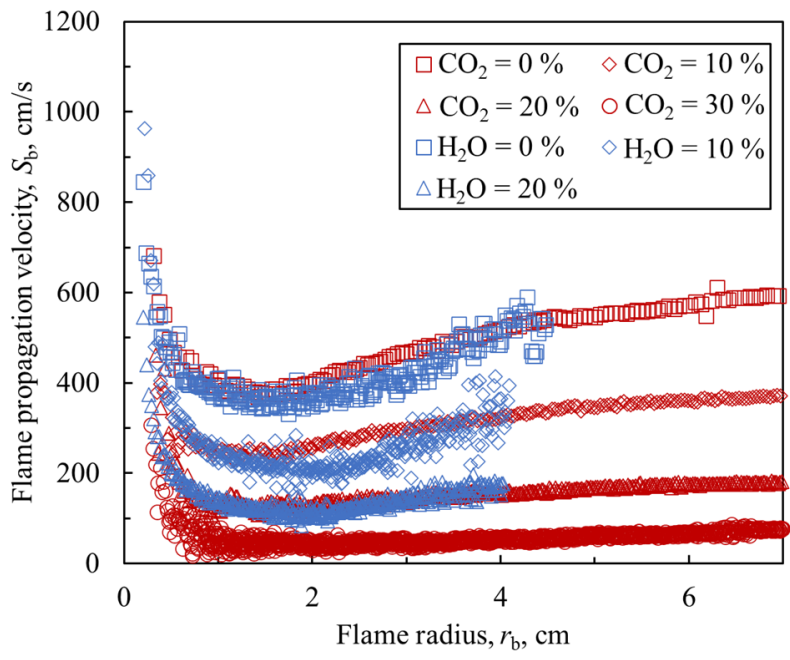

Fig. 12 Flame propagation velocity depending on the flame radius at $\phi=0.5$

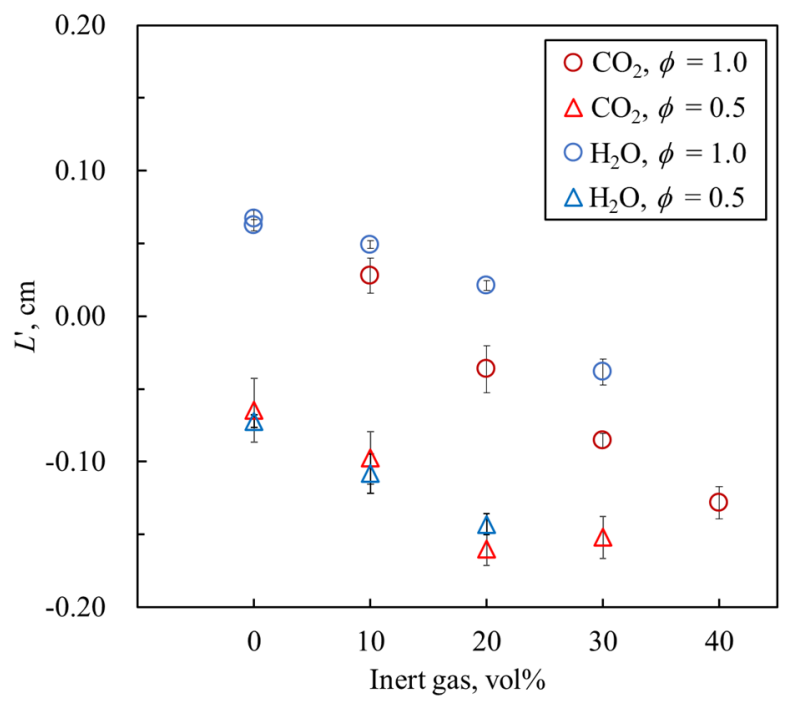

Fig. 14 Markstein length including the thermalexpansion effect depending on the concentration of inert gas at $\phi=1.0$ and 0.5 


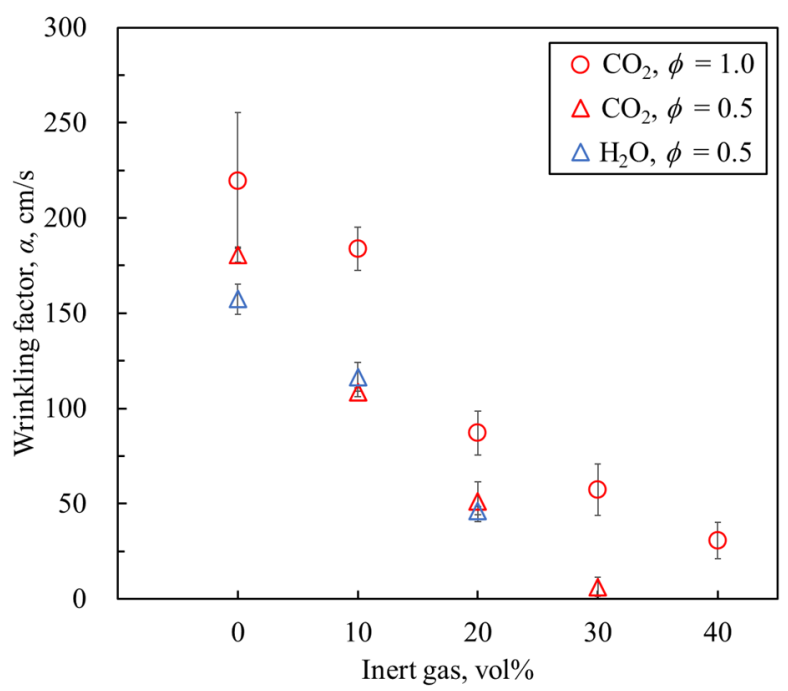

Fig. 15 Wrinkling factor depending on the concentration of inert gas at $\phi=1.0$ and 0.5

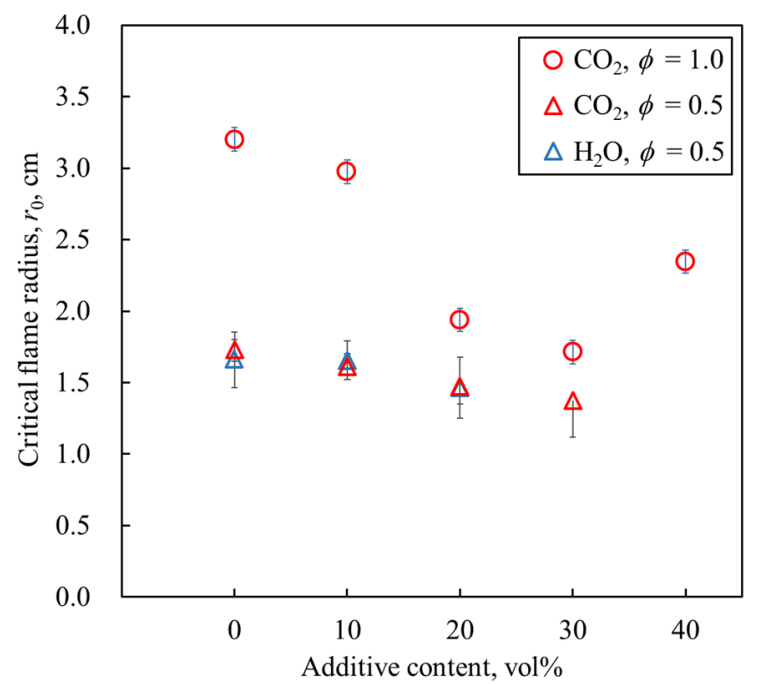

Fig. 16 Critical flame radius depending on the concentration of inert gas at $\phi=1.0$ and 0.5

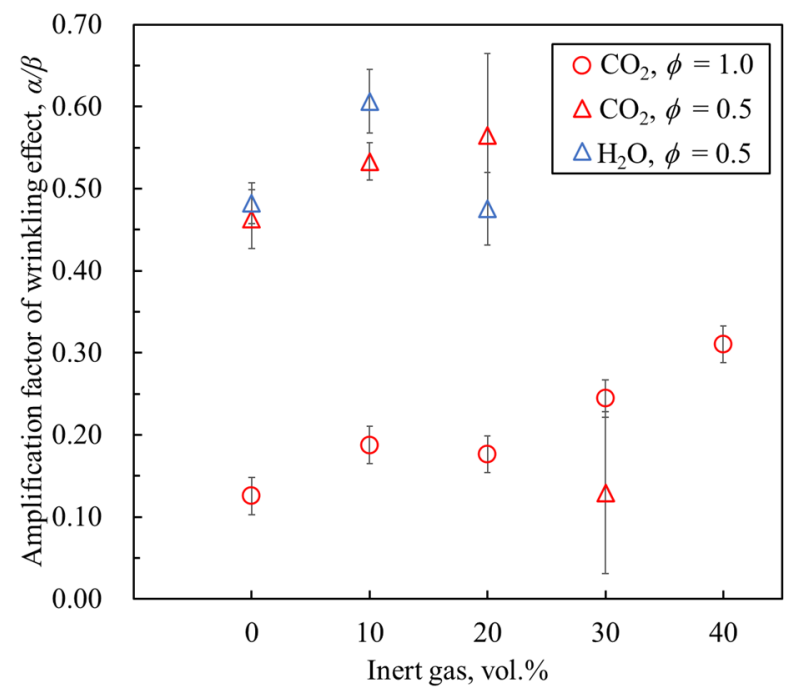

Fig. 17 Normalized wrinkling factor depending on the concentration of inert gas at $\phi=1.0$ and 0.5

\section{Conclusions}

We have performed the experiments of hydrogen explosion in two types of closed chambers and observed spherically expanding flames using Schlieren photography. The obtained results in the experiments are as follows:

1. Wrinkles on the flame surface become clear with increasing the flame radius. Prominent wrinkled surface is observed at low equivalence ratios, which is because that diffusive-thermal instability becomes stronger. 
2. The propagation velocity increases monotonically as the flame radius becomes larger. We find the appearance of flame acceleration, which is caused by the evolution of wrinkles on the flame surface.

3. The Markstein length decreases as the concentration of inert gas becomes higher, indicating that the addition of inert gas promotes the instability of hydrogen flames.

4. The wrinkling factor decreases as the inert-gas concentration becomes higher. The normalized wrinkling factor increases, on the other hand, under the conditions of high inert-gas concentration. This indicates that the addition of $\mathrm{CO}_{2}$ or $\mathrm{H}_{2} \mathrm{O}$ promotes the unstable motion of hydrogen flames, which could be due to the enhancement of the diffusivethermal instability.

5. Based on the characteristics of dynamic behavior of hydrogen flames, the parameters used in the mathematical model on propagation velocity is obtained. Thus, we can predict the flame propagation velocity under various conditions.

In the present study, we elucidate the effects of inert gases, $\mathrm{CO}_{2}$ or $\mathrm{H}_{2} \mathrm{O}$, on the dynamic behavior of hydrogen/air premixed flames at $\phi=1.0$ and 0.5 . In the near future, we will perform the experiments under high- and low-pressure environments to reveal the effects of pressure on the characteristics of hydrogen explosion. Moreover, we will treat other inert gases in the experiments of hydrogen explosion to validate the mathematical model on propagation velocity including flame acceleration. 
Katsumi, Yoshida, Nakagawa, Yazawa, Kumada, Sato, Aung, Chaumeix and Kadowaki,

Journal of Thermal Science and Technology, Vol.16, No.2 (2021)

\section{References}

Acar, C., Dincer, I., The potential role of hydrogen as a sustainable transportation fuel to combat global warming, International Journal of Hydrogen Energy, Vol. 45, No. 5 (2020), pp. 3396-3406, DOI: 10.1016/j.ijhydene.2018.10.149.

Bane, S.P.M., Mével, R., Coronel, S.A., Shepherd, J.E., Flame burning speeds and combustion characteristics of undiluted and nitrogen-diluted hydrogen-nitrous oxide mixtures, International Journal of Hydrogen Energy, Vol. 36, No. 16 (2011), pp. 10107-10116, DOI: 10.1016/j.ijhydene.2011.04.232.

Cheikhravat, H., Goulier, J., Bentaib, A., Meynet, N., Chaumeix, N., Paillard, C.-E., Effects of water sprays on flame propagation in hydrogen/air/steam mixtures. Proceedings of the Combustion Institute, Vol. 35, No. 3 (2015), pp. 2715-2722, DOI: 10.1016/j.proci.2014.05.102.

Duan, J., Liu, F., Laminar combustion characteristics and mechanism of hydrogen/air mixture diluted with $\mathrm{N} 2+\mathrm{H} 2 \mathrm{O}$. International Journal of Hydrogen Energy, Vol. 42, No. 7 (2017), pp. 4501-4507, DOI: 10.1016/j.ijhydene.2016.10.071.

Dutta, S., A review on production, storage of hydrogen and its utilization as an energy resource, Journal of Industrial and Engineering Chemistry, Vol. 20, No. 4 (2014), pp. 1148-1156, DOI: 10.1016/j.jiec.2013.07.037.

Gong, Y., Huang, X., Deng, J., Li, L., Experimental and numerical study on combustion characteristics of super lean $\mathrm{H}_{2}-\mathrm{O}_{2}$ premixed laminar flame in argon atmosphere, International Journal of Hydrogen Energy, Vol. 45, No. 41 (2020), pp. 21956-21968, DOI: 10.1016/j.ijhydene.2020.05.179.

Haseli, Y., Maximum conversion efficiency of hydrogen fuel cells, International Journal of Hydrogen Energy, Vol. 43, No. 18 (2018), pp. 9015-9021, DOI: 10.1016/j.ijhydene.2018.03.076.

Iijima, T., Takeno, T., Effects of temperature and pressure on burning velocity, Combustion and Flame, Vol. 65, Issue 1 (1986), pp. 35-43

International Atomic Energy Agency (IAEA), Mitigation of hydrogen hazards in nuclear power plants (online), available from < https://www.iaea.org/publications/8646/mitigation-of-hydrogen-hazards-in-severe-accidents-innuclear-power-plants $>$.

Katsumi, T., Aida, T., Aiba, K., Kadowaki, S., Outward propagation velocity and acceleration characteristics in hydrogen-air deflagration, International Journal of Hydrogen Energy, Vol. 42 (2017a), pp. 7360-7365.

Katsumi, T., Aida, T., Aiba, K., Aung, T.T., Kadowaki, S., Temperature influence on the dynamic behavior and flame acceleration of spherically expanding hydrogen flames, Journal of the Combustion Society of Japan (in Japanese), Vol. 59, No. 189 (2017b), pp. 210-215, DOI: 10.20619/jcombsj.59.189_210.

Kim, W.K., Mogi, T., Kuwana, K., Dobashi, R., Acceleration phenomena of expanding spherical flames in hydrogen/air mixtures for large-scale gas explosions, Journal of the Combustion Society of Japan (in Japanese), Vol. 56, No. 175(2014), pp. 74-79, DOI: 10.20619/jcombsj.56.175_74.

Kitagawa, T., Effects of pressure on spherically propagating premixed flames, Journal of the Combustion Society of Japan (in Japanese), Vol. 56, No. 175 (2014), pp. 15-22.

Lamoureux, N., Chaumeix, N., Paillard, C.-E., Laminar flame velocity determination for $\mathrm{H}_{2}-$ air- $-\mathrm{He}-\mathrm{CO}_{2}$ mixtures using the spherical bomb method, Experimental Thermal and Fluid Science, Vol. 27 (2003), pp. 385-393.

Li, H.-M., Li, G.-X., Sun, Z.-Y., Zhou, Z.-H., Li, Y., Yuan, Y., Fundamental combustion characteristics of lean and stoichiometric hydrogen laminar premixed flames diluted with nitrogen or carbon dioxide, Journal of Engineering for Gas Turbines and Power, Vol. 138, No. 11 (2016), pp. 111501, DOI: 10.1115/1.4032315.

Li, Y., Bi, M., Huang, L., Liu, Q., Li, B., Ma, D., Gao, W., Hydrogen cloud explosion evaluation under inert gas atmosphere, Fuel Processing Technology, Vol. 180 (2018), pp. 96-104, DOI: 10.1016/j.fuproc.2018.08.015.

Li, Y., Bi, M., Yan, C., Liu, Q., Zhou, Y., Gao, W., Inerting effect of carbon dioxide on confined hydrogen explosion, International Journal of Hydrogen Energy, Vol. 44, No. 40 (2019), pp. 22620-22631, DOI: 10.1016/j.ijhydene.2019.04.181.

Liu, F., Bao, X., Gu, J., Chen, R., Onset of cellular instabilities in spherically propagating hydrogen-air premixed laminar flames, International Journal of Hydrogen Energy, Vol. 37, No. 15 (2012), pp. 11458-11465, DOI: 10.1016/j.ijhydene.2012.05.013.

Mazloomi, K., Gomes, C., Hydrogen as an energy carrier: Prospects and challenges, Renewable and Sustainable 
Energy Reviews, Vol.16, No. 5 (2012), pp. 3024-3033, DOI: 10.1016/j.rser.2012.02.028.

Morovatiyan, M., Shahsavan, M., Aguilar, J., Mack, J.H., Effect of argon concentration on laminar burning velocity and flame speed of hydrogen mixtures in a constant volume combustion chamber, Journal of Energy Resources Technology (2020), DOI: 10.1115/1.4048019 (in press).

Newell, R., Raimi, D., Villanueva, S., Prest, B., Global energy outlook 2020: Energy transition or energy addition? (online), available from $<$ https://www.rff.org/publications/reports/global-energy-outlook2020/\#: :text=Key\%20Findings\&text=The\%20International\%20Energy\%20Agency\%20(IEA,renewables\%20wo uld\%20grow\%20by\%201\%25.>.

Niaz, S., Manzoor, T., Pandith, A.H., Hydrogen storage: Materials, methods and perspectives, Renewable and Sustainable Energy Reviews, Vol. 50 (2015), pp. 457-469, DOI: 10.1016/j.rser.2015.05.011.

Qiao, L., Gu, Y., Dahm, W.J.A., Oran, E.S., Faeth, G.M., A study of the effects of diluents on near-limit H2-air flames in microgravity at normal and reduced pressures, Combustion and Flame, Vol. 151, No. 1-2 (2007), pp. 196-208, DOI: 10.1016/j.combustflame.2007.06.013.

Sun, Z.Y., Liu, F.S., Bao, X.C., Liu, X.H., Research on cellular instabilities in outwardly propagating spherical hydrogen-air flames, International Journal of Hydrogen Energy, Vol. 37, No. 9 (2012), pp. 7889-7899, DOI: 10.1016/j.ijhydene.2012.02.011.

Wang, L.-Q., Ma, H.-H., Shen, Z.-W., Explosion characteristics of hydrogen-air mixtures diluted with inert gases at sub-atmospheric pressures, International Journal of Hydrogen Energy, Vol. 44, No. 40 (2019), pp. 22527-22536, DOI: 10.1016/j.ijhydene.2019.01.059.

Williams, F.A., Combustion theory, Second edition (1985), pp. 349-365, CRC Press, 10.1201/9780429494055.

Yan, C., Bi, M., Li, Y., Gao, W., Effects of nitrogen and carbon dioxide on hydrogen explosion behaviors near suppression limit, Journal of Loss Prevention in the Process Industries, Vol. 67 (2020), pp. 104228, DOI: 10.1016/j.jlp.2020.104228.

Yang, S., Saha, A., Wu, F., Law, C.K., Morphology and self-acceleration of expanding laminar flames with flame-front cellular instabilities, Combustion and Flame, Vol. 171 (2016), pp. 112-118, DOI:

10.1016/j.combustflame.2016.05.017.

Zhang, W., Chen, Z., Kong, W., Effects of diluents on the ignition of premixed H2/air mixtures, Combustion and Flame, Vol. 159, No. 1 (2012), pp. 151-160, DOI: 10.1016/j.combustflame.2011.05.017. 